\title{
MODELOS APLICABLES EN MEDIACIÓN INTERCULTURAL
}

\author{
APPLICABLE MODELS IN INTERCULTURAL MEDIATION
}

\author{
Carmelo Hernández Ramos \\ Universidad de Alicante. España/Spain \\ carmelo.hernandez@ua.es
}

Recibido/Received: 11/08/2014

Modificado/Modified: 20/08/2014

Aceptado/Accepted: 23/09/2014

\section{RESUMEN}

Una concepción inclusiva de la cultura debe necesariamente resaltar su carácter diverso y cambiante. Partiendo de este enfoque, que permite abordar la cuestión migratoria teniendo en cuenta el factor étnico, junto a otros elementos esenciales que vertebran su multidimensionalidad, perfilaremos la mediación intercultural desde la perspectiva de su aplicabilidad en situaciones sociales de multiculturalidad significativa, planteamiento que permite promover la igualdad y el respeto a la diferencia, junto a la interacción positiva entre las partes, poniendo el acento sobre lo que se tiene en común. A tal fin, analizaremos los principales modelos aplicables en mediación intercultural, trazando un perfil del papel del mediador y las características del proceso.

\section{PALABRAS CLAVE}

Cultura inclusiva, resolución de conflictos, mediación, factor étnico, modelo lineal, modelo transformativo.

\section{SUMARIO}

1. Introducción. 2. Modelo Tradicional Lineal (Harvard). 3. Modelo Transformativo (Bush y Folger). 4. Modelo Circular Narrativo (Sara Cobb). 5. Programación neuro-lingüística y proceso de mediación. 6. Epílogo. Bibliografía.

\begin{abstract}
An inclusive conception of the culture must to highlight its diverse and changeable character. Departing from this approach, which allows to tackle the migratory topic, bearing in mind the ethnic factor, along with other multidimensional elements, we will outline the intercultural mediation from the perspective of its applicability in social situations of significant multiculturalism, to promote equality and respect for difference, next to the positive interaction between the parts, putting emphasis on what it has been in common. In fact, we will analyze the main applicable models in intercultural mediation, drawing up a profile of the professional role of the mediator and the characteristics of the process.
\end{abstract}

\section{KEYWORDS}

Inclusive culture, conflict resolution, mediation, ethnic factor, linear model, transformational model. 


\section{CONTENTS}

1. Introduction. 2. Traditional Linear Model (Harvard). 3. Transformative Model (Bush and Folger).

4. Circular Narrative Model (Sara Cobb). 5. Neuro-linguistic programming and mediation. 6. Epilogue. References

\section{INTRODUCCIÓN}

A pesar de que el término mediación intercultural es de dominio público y goza de una amplia difusión, lo cierto y verdad es que, en el contexto de los distintos modelos de mediación aplicables, la mediación intercultural necesita de una clara fundamentación conceptual, que sirva para encuadrar su propio perfil dentro del marco unitario y, a la vez, diverso de la mediación.

Es esencial para ello determinar con claridad cómo aplicar los principales modelos de mediación en contextos interculturales, partiendo de una revisada definición de mediación intercultural, a la que caracterizaremos como la intervención de un tercero neutral, imparcial e independiente, en una situación de interacción social, personal, comunitaria o institucional, en la que entran en juego factores multiculturales significativos, que condicionan el curso de la interacción y su evolución, con la finalidad de facilitar, mediante su acción mediadora, el acercamiento entre las personas en conflicto, partiendo del reconocimiento recíproco del otro enfrentado, mediante la comunicación asertiva, el compromiso de coexistencia basado en la aceptación muta y la regulación del conflicto desde el aprendizaje de estrategias consensuadas de cogestión entre las partes, actores sociales o agentes institucionales, etnoculturalmente diferenciados, buscando relaciones igualitarias a través de soluciones interculturalmente satisfactorias.

Presentaremos a continuación, partiendo de la definición enunciada, los tres modelos de mediación más representativos, destacando, en cada caso, los principales elementos característicos de cada línea de pensamiento y sus correspondencias más relevantes con la perspectiva intercultural.

\section{MODELO TRADICIONAL LINEAL (HARVARD)}

El modelo de Harvard es esencialmente una escuela de negociación asistida para la resolución de conflictos. En equipo de Harvard ha sobresalido por su extraordinaria capacidad para intervenir exitosamente en diferentes niveles de negociación, tanto nacionales como internacionales.

En su publicación de 1981, Getting To Yes: Negotiating Agreement Without Giving In, que podríamos traducir como "Obtenga el Sí: Negociación de acuerdos sin concesiones", Roger Fisher y William Ury dieron carta de naturaleza al denominado "Método Fisher-Ury", que parte de la consideración de cuáles deberían ser los elementos esenciales a considerar en toda negociación para obtener un acuerdo sin ceder frente a la otra parte. El contenido esencial de su línea de pensamiento, basada en la aplicación de una estrategia de negociación que ayude a proteger los propios intereses sin descuidar el entendimiento y la búsqueda de cooperación con la otra parte, a sabiendas de que se interesa justamente por los intereses contrarios, será objeto de análisis y síntesis, a continuación, en la Tabla 1. Tomaremos como 
referencia la edición original, Getting To Yes: Negotiating Agreement Without Giving In de Fisher y Ury, publicada en los Estados Unidos por Houghton Mifflin Company, 1981.

Tabla 1

\begin{tabular}{|l|l|}
\hline Personas & $\begin{array}{l}\text { Los negociadores son personas y, por consiguiente, la relación interpersonal puede } \\
\text { entremezclarse, de una forma otra, con el problema a abordar. Será prioritario, por } \\
\text { tanto, en toda negociación actuar sobre el problema de las personas implicadas, } \\
\text { enfrentándose directamente al problema, nunca a las personas. }\end{array}$ \\
\hline Intereses & $\begin{array}{l}\text { Precisamente porque los intereses definen la entidad real del problema, hay que } \\
\text { centrarse en los intereses, no en las posiciones o posturas de las partes. El mediador } \\
\text { deberá ser capaz de descubrir e identificar intereses compartidos y compatibles, por } \\
\text { encima de las posturas enfrentadas en la negociación. }\end{array}$ \\
\hline Opciones & $\begin{array}{l}\text { El mediador ha de saber inventar opciones creativas, a través de la búsqueda o } \\
\text { procura de más de una única respuesta (solución) al problema suscitado, partiendo de } \\
\text { una visión de la mediación centrada en los beneficios mutuos, evitando hacer juicios } \\
\text { de valor y aportando decisiones que sean fáciles de ejecutar. }\end{array}$ \\
\hline Criterios & $\begin{array}{l}\text { Es imprescindible saber usar criterios objetivos, independientes de la voluntad } \\
\text { individual de cada parte en conflicto, para poder desarrollar las opciones de beneficio } \\
\text { mutuo identificadas, y poder concluir el acuerdo con eficacia y consenso (voluntad } \\
\text { compartida). }\end{array}$ \\
\hline
\end{tabular}

En este modelo el tipo de comunicación es lineal y bilateral, mediante preguntas abiertas, evitando los interrogatorios cerrados que limitan la flexibilidad de las respuestas. Es esencial potenciar la aireación del conflicto y animar a los sujetos enfrentados a que eviten retrotraerse al pasado, poniendo especial énfasis en el futuro. Esta previsión resultará fundamental para restaurar o instalar el equilibrio entre las partes, desactivando las emociones negativas y revalorizando los puntos de encuentro detectados.

Es proceso estructurado, aunque no rígido, durante el cual el mediador, procura facilitar la comunicación y la interacción entre las partes con el fin de disminuir las diferencias y tensiones preexistentes para lograr el acuerdo y superar las disputas. Es esencial, para ello, que los participantes puedan expresar con claridad sus intereses y el modo de satisfacerlos, con independencia del contexto en el cual se desarrollan los conflictos

Desde esta perspectiva, que pone el énfasis en establecer canales de comunicación entre las partes con la finalidad de alcanzar un acuerdo sin más, la mediación sería "exitosa", por tanto, cuando se llega a dicho acuerdo. Esta aparente simpleza o simplificación, consistente en buscar una solución práctica, lo antes posible, fácil de aplicar y directamente entendible y asumible por las personas mediadas, es más una virtud que un defecto del modelo FisherUry. Cualquier mediador que disponga de una proyección profesional suficiente, es conocedor de que la excesiva prolongación de un proceso de mediación conduce generalmente al abandono de las partes y tiene además, como efecto colateral adverso, la generación de un acentuado sentimiento de frustración en las personas afectadas, tanto mediadores como mediados.

Sin embargo, en su texto de 1996, Mediación. Conducción de disputas, comunicación y técnicas, publicado por la editorial Paidós Ibérica, Marines Suares califica al Modelo Tradicional Lineal de Harvard como limitativo desde el ámbito de la mediación intercultural, fundamentalmente porque el modelo de Harvard se basa en una concepción lineal de la causalidad, en realidad, el propio desacuerdo, y en mediación intercultural lo habitual es que 
los factores intervinientes, por defecto, siempre sean varios y diversos. En suma, hemos de precisar en este punto que en mediación intercultural pueden darse situaciones específicas que requieran de un proceso más complejo y dilatado en el tiempo. En estos supuestos, la aplicación stricto senso del método Fisher-Ury no estaría, por tanto, indicada.

Ahora bien, a pesar de esta circunstancia, no debemos olvidar que el medidor intercultural es, en esencia, un facilitador de la comunicación entre individuos caracterizados por su diferenciación cultural: ciudadanos autóctonos y extranjeros, personas pertenecientes a una cultura minoritaria y otras que forman parte de la cultura mayoritaria, individuos de una etnia y sujetos pertenecientes a otra..., etc. En todos estos casos, la capacidad del profesional para establecer un canal de comunicación imparcial, que identifique y neutralice los malos entendidos, es esencial para el progreso de la mediación intercultural. Esa capacidad para fomentar y establecer un diálogo constructivo entre los mediados, a pesar de las limitaciones de la comunicación lineal bilateral, es sin embargo esencial para que el proceso de mediación avance y se retroalimente positivamente.

En el modelo tradicional lineal, la fase inicial comporta una clara estrategia de intervención mediatoria, basada en la prevalencia, sobre cualquier otra línea de interacción entre personas, de la comunicación verbal directa. Para una mayor efectividad estratégica, es posible separar a las personas (y sus problemas), lo que evita situaciones de tensión y culpabilización mutua de la situación conflictiva, siendo el propio mediador el mejor vehículo de transmisión de información y focalización de los intereses comunes y opciones de beneficio mutuamente consensuado.

Queda claro, por tanto, que en mediación intercultural, romper los monólogos, la comunicación unidireccional sin escucha activa del mensaje del otro interlocutor, y por tanto el aprovechamiento óptimo del modelo de comunicación bidireccional efectiva, con sus propias limitaciones, es fundamental para llegar a la fase de acuerdo con la mejor perspectiva posible. Una vez alcanzada la meta, es decir, la consecución del acuerdo, el efecto es intrínsecamente terapéutico y se deja sentir en las personas que han conseguido llegar, mejorando la relación inter-partes o, al menos, su evolución de forma sostenible en el tiempo

\section{MODELO TRANSFORMATIVO (BUSH Y FOLGER)}

En 1994, año recordado por muchos eventos importantes y otros realmente lamentables, como el inicio de la rebelión social en Chiapas (México) o el sangriento enfrentamiento intertribal en Ruanda protagonizado por las etnias de los hutus y los tutsis, que arrojó el dramático saldo de cerca de 800.000 víctimas mortales y más de dos millones de refugiados, en ese mismo año, Bush y Folger publicaron un nuevo texto que abrió, en materia de mediación, una nueva visión acerca de cómo afrontar el conflicto a través del fortalecimiento propio y el reconocimiento de los otros. De hecho, en La promesa de la mediación, más allá de la consecución de un acuerdo, Bush y Folger defienden, como objetivo primordial de la mediación, la consecución de la mejorar sustancial de las relaciones entre los sujetos enfrentados mediante la transformación del conflicto en fuente de conocimiento a través de la asertividad y la empatía. El conflicto puede ser, en sí mismo, una oportunidad de crecimiento personal y la mediación se convierte entonces en el vehículo perfecto para aprovechar esa oportunidad.

La finalidad principal de la Escuela Transformativa consiste, por tanto, en modificar la relación entre las partes, por lo que no se pone tanto énfasis en obtener un acuerdo, aunque por supuesto este sea el objetivo final a alcanzar, pero su logro se pondera como una suerte 
de consecuencia de esa nueva situación producida entre las partes, como resultado de la transformación producida en la relación existente entre las personas mediadas. El acuerdo sólo se logrará en la medida que los participantes encuentren una nueva mirada del otro ("outside") y de sí mismos ("inside").

Para lograr este objetivo, se programan reuniones conjuntas o privadas, al igual que en el modelo Harvard, en las que se intenta modular la comunicación entre las personas intervinientes en la mediación desde una perspectiva quasi terapéutica, procurando influir decisivamente en la trasformación de la situación causante del núcleo del conflicto, para buscar un acuerdo, a través de la transformación "desde dentro y hacia fuera" de la mutua percepción y recíproca comprensión tanto de las causas como también de los posibles azares que determinaron su emergencia. En las entrevistas, el mediador procurará que cada parte se sienta protagonista de la transformación operada y pueda así reconocer tanto su cuota de responsabilidad en el desenvolvimiento de la controversia como también la que le corresponde a su oponente.

En el Modelo Transformativo se alcanza el éxito cuando las partes cambian ("se transforman") para mejorar, a través del propio proceso de mediación. La mediación, por tanto, será exitosa no solo cuando se llega a un acuerdo, sino especialmente cuando además del acuerdo alcanzado, éste es consecuencia o resultado de la transformación positiva de la situación de conflicto o crisis preexistente. Ello supone que se ha debido producir un objetivo mejoramiento de la situación entre las partes, comparada con la que había antes del acuerdo.

En su esencial artículo de 2001, "Modelos de mediación y su aplicación en mediación intercultural", Carlos Giménez establece con claridad que los dos elementos centrales del modelo trasformativo son la revalorización de la autoestima y el recíproco reconocimiento de las (co)responsabilidades mutuas. Contextualizaremos, a continuación, el significado de ambas expresiones, en la perspectiva de la mediación intercultural:

La revalorización ("empowerment") se traduce en que los propios mediados adquieren conciencia y toman acción consecuente, por la responsabilidad de sus acciones. El significado que el término "empowerment" adquiere en la mediación intercultural es relacional antes que individual, pues esa revalorización o empoderamiento no es "sobre el otro" sino que se adquiere "con el otro" y es convergente y recíproca. Es la situación de reciprocidad y equidistancia relacional la que revaloriza y empodera a las partes. La revalorización es esencial para promover, en un sentido amplio, una nueva cultura ciudadana e institucional en la resolución pacífica de conflictos y, por tanto, de forma específica, en las complejas relaciones interétnicas o de interculturalidad, donde es esencial, por un lado, controlar y evitar malos entendidos que provoquen explosiones de violencia o agresividad y, por otro, fomentar la visión del aprovechamiento de la oportunidad que ofrece el medio (la mediación) para llegar a un resultado satisfactorio. Es entonces cuando el manejo de los recursos disponibles y su distribución igualitaria se convierten en uno de los ejes troncales de la mediación intercultural, puesto que las personas migrantes desconocen le legislación autóctona, la disponibilidad de los medios técnicos y recursos humanos disponibles..., etc. Es, por tanto, esencial conocer el valor funcional e instrumental de las diferentes culturas en juego para alcanzar una fértil y productiva utilización de los recursos disponibles.

Probablemente la aplicación más elocuente del "empowerment", en mediación intercultural, se pueda apreciar en la adopción de las decisiones relevantes a lo largo del proceso de mediación y en la significación de la corresponsabilidad implícita en el propio acto de decidir y acordar. Antes de decidir es fundamental que el mediado sea capaz de evaluar las fortalezas $\mathrm{y}$, especialmente, las debilidades de su propio posicionamiento. 
La Mediación Transformadora, por tanto, puede responder realmente bien en el ámbito de la mediación intercultural, porque coloca el acento en la revalorización de la autoestima y el mutuo reconocimiento de las responsabilidades que se contraen en el acuerdo. La mediación intercultural, por definición, debe ir "más-allá-del-conflicto". Es decir, debe transformar realmente la divergencia, el malentendido, el desajuste..., etc. En el modelo de Bush y Folger, la mediación transformativa debe ir "más-allá-del-acuerdo". Son, por tanto, dos objetivos cuya convergencia es parte de un planteamiento en el que ambas partes resultan revalorizadas cuando, a través de la mediación, aprenden, comprenden y adquieren o aumentan los siguientes elementos de progreso y conocimiento, que Bush y Folger describen de manera más extensa, en su texto La promesa de la mediación, pp. 135 a 137, y que aquí resumiremos a continuación:

- Alcanzar una comprensión más clara de la verdadera dimensión del problema, comparada con la que se tenía antes de la mediación.

- Comprender más claramente cuáles son sus metas e intereses en la situación transformada, al valorar el logro de su consecución desde el respeto hacia la posición e intereses de la otra parte ("el otro").

- Adquirir conciencia de la posible gama de alternativas a través de las cuales pueden lograr la satisfacción de sus intereses, ejerciendo un control (co)responsable sobre esas mismas alternativas.

- Comprender que existen decisiones adecuadas e inadecuadas, con respecto a lo que se debe hacer o no hacer en la situación transformada, por lo que es esencial aprender a ejercer un control responsable sobre dichas decisiones.

- Acrecentar las propias habilidades en la resolución de conflictos.

- Aprender a escuchar, comunicar, evaluar soluciones..., etc., y ser capaz de aplicar lo aprendido en el proceso de mediación.

- Adquirir conciencia o renovarla a cerca de los recursos disponibles para alcanzar las metas y objetivos planteados.

- Comprender el alcance de sus recursos y la posibilidad de aumentar su efectividad en el proceso de mediación.

- Adoptar decisiones con clara conciencia de su alcance y de las posibilidades de acordar y cómo hacerlo.

- Evaluar las fortalezas y debilidades de los argumentos de parte y contrarios, así como las ventajas y desventajas de las posibles soluciones y alternativas, como modus operandi en la adopción de decisiones.

En cuanto a la expresión el reconocimiento de las (co)responsabilidades mutuas, Bush y Folger indican claramente que depende del grado de revalorización ("empowerment") adquirido previamente por los sujetos mediados.

En mediación intercultural, esta categoría cobra una especial significación, puesto que resulta esencial que cada parte sea capaz de reconocer la diferencia y singularidad de la otra, es decir, sus signos de identidad. El mediador ha de ser capaz de gestionar de modo positivo esas diferencias culturales, raciales, lingüísticas..., etc., para evitar que sean causa de exclusión, promoviendo la empatía equidistante en el respeto a la singularidad del otro. "Calzarse los zapatos del otro" es una expresión muy gráfica que representa muy bien la importancia de comprender la situación del otro (legal, laboral, económica, incluso "personal") para alcanzar un acuerdo transformativo. Ser capaz de proporcionar feedback acerca de los cambios experimentados en la mediación es otro factor de protección intrínseco 
al proceso transformativo. Es la mejor manera de promover un clima situacional estratégico para favorecer la disensión y el acuerdo.

La integración sociocultural de las personas migrantes debe concebirse como proceso de mutua adaptación entre la población autóctona (receptora) y la inmigrante (extranjera). Cobra así una especial significación la adaptación a los recursos institucionales esenciales de acogida, como la escuela, la sanidad, los servicios sociales, el sistema judicial..., etc., que generalmente son configurados teniendo en cuenta únicamente las características de la población autóctona, a la multiculturalidad y diversidad de los ciudadanos inmigrantes. En sentido recíproco, la población migrante ha de ser capaz de adaptarse a la legitimidad normativa y social de la sociedad autóctona y reconocer la importancia de aprovechar las oportunidades del entorno.

El reconocimiento de la posición "del otro" implica experimentar un sentimiento de empatía, en un sentido amplio, respecto del conflicto que comparten y las cualidades que se han de esgrimir y poner en circulación para solucionar transformativamente el conflicto. Sintetizaremos a continuación este estratégico elemento, desarrollado originalmente por Bush y Folger en La promesa de la mediación, pp. 137 a 144, afirmando que una parte otorga el reconocimiento en la mediación a la otra cuando se comprenden, aceptan y admiten los siguientes elementos de progreso y conocimiento:

- Comprender empáticamente la posición “del otro" y valorar los sentimientos comunes a ambas posiciones, demostrando esa compresión proactivamente en las sesiones del proceso de mediación.

- Percibir al otro mediado de forma significativamente positiva respecto de la visión inicialmente estructurada.

- Aceptar el punto de vista "del otro" y ser capaz de ver el conflicto y su solución desde la perspectiva contraria.

- Admitir la transformación perceptiva experimentada y los cambios de interpretación "del otro" y ser capaz de dar traslado (feedback) de esa vivencia interior al otro mediado y/o al mediador.

- Promover una adaptación "al otro" por referencia concreta el modo consensuado de afrontamiento y resolución del conflicto. Si no resultara posible, ser capaz de cerrar el proceso de mediación desde una sincera posición de pesar por la imposibilidad habida.

Mediante la exposición de un ya clásico caso práctico, que no vamos a reproducir aquí, pues puede ser consultado directamente en "La promesa de la mediación", pp. 281 a 295, Bush y Folger describen cuáles son las tres pautas del proceso de mediación transformativa, que resumiremos a continuación:

1.- El mediador ha de seguir a las partes en el proceso de mediación, estando atento a sus contribuciones, comentarios, exposición de alternativas, preguntas, cuestionamiento de la posición del otro y valoración de posibles formas de acuerdo. El mediador no busca un acuerdo como única finalidad, es decir, un acuerdo per se. Lo que persigue teleológicamente es la revalorización de la autoestima y el recíproco reconocimiento de las corresponsabilidades mutuas

2.- El mediador ha de estimular a lo largo del proceso de mediación la deliberación interpartes y favorecer la adopción consensuada de decisiones.

3.- El mediador ha de promover las oportunidades de aprovechamiento de las perspectivas argumentadas por las partes. 
En cada sesión se estrecharán y reducirán las deliberaciones, a medida que se vayan agotando las oportunidades, de ahí que el mediador, interviene para promover un campo más amplio de oportunidades de habilitación y reconocimiento entre las partes. Cuando ese campo se agota, el proceso de mediación debe llegar a su fin. El mediador resumirá los logros y los compromisos y, posteriormente, las partes procederán a redactar el enunciado final.

Este enfoque singulariza el trabajo del mediador, que partiendo de los roles y patrones culturales de la persona migrante, los pone en valor y correspondencia respecto de aquellos que han sido compartidos con los ciudadanos autóctonos, analizando sinergias, convergencias o divergencias en comunicación interactiva, transaccional o interrelacional para resolver los posibles conflictos en trámite corresponsablemente, minimizando -en el proceso- las interferencias producidas por procesos de inferiorización, guetización, racialización y cualquier otro presente en un contexto multicultural significativo.

\section{MODELO CIRCULAR NARRATIVO (SARA COBB)}

Entre el 13 y el 15 de junio de 2004 tuvo lugar en la ciudad de Barcelona el Diálogo "Los conflictos en la vida cotidiana", organizado por el Fórum Universal de las Culturas. La sesión inaugural contó con la presencia de tres importantes personalidades de la mediación: Sara Cobb, Kenneth Gergen y Humberto Maturana. Tener la oportunidad de ver y escuchar a Sara Cobb en un contexto tan productivo y avanzado ha sido una de las experiencias de impacto que más huella han dejado en mi memoria experiencial conectada con la mediación y sus posibilidades.

Sara Cobb defendió en el Diálogo, con convicción y criterio, que "es preciso buscar espacios de encuentro que permitan la reflexión y la comunicación entre la gente", a la par que coincidía con sus dos compañeros de mesa en que "la democracia es más una cultura que un método, una forma de hacer cultura cotidiana que desaparece cuando se deja de potenciar". La directora del Instituto de Análisis y Resolución de Conflictos de la Universidad George Mason de Estados Unidos, concluyó su intervención con una de esas reflexiones que dejan abierto el camino hacia la construcción de un nuevo marco de relaciones entre las personas en el que la mediación puede ser una de las herramientas más poderosas de resolución de conflictos disponible para la humanidad: "no se puede pensar en control y mucho menos cuando se trata de la vida de los demás", pues "todos los cambios requieren conductas personales y relacionales que son siempre difíciles".

A continuación procederemos a resumir las principales notas características del Modelo Circular Narrativo de Sara Cobb, a partir de las precisas indicaciones de la autora acerca de la deconstrucción de la neutralidad en mediación ("Deconstructing neutrality in mediation", en Law and Social Inquiry 161: 35-62) y la construcción y transformación de las narraciones en la mediación comunitaria ("The construction and transformation of narratives in community mediation", en Studies in law, politics and society: Volume 11, Greenwich: CT, JAI Press).

Partiendo del supuesto de que el ser humano vive en una permanente pulsión entre "deseo" y "deber", el Modelo Circular Narrativo sostiene que, en las relaciones humanas, "conflicto" no equivale necesariamente a "antagonismo y/o agresión", sino que, por el contrario, el núcleo de su contenido semántico debe ser re-definido y re-conceptualizado. Desde esta perspectiva, "conflicto" equivaldría a "una suerte de presencia interna y casi continua en la existencia de cada persona". 
El Modelo Circular Narrativo diferencia entre "conflicto" y "disputa". Esta última sería el conflicto generado entre dos o más personas cuando se hace público e inmanejable para ellos, mientras que el conflicto se daría fundamentalmente en el plano de la comunicación, esto es, no solo en el contenido de lo que se dice sino en el cómo se dice y de qué manera la emisión del mensaje es percibida por el receptor. Pone, por tanto, énfasis en la comunicación, y parte de una concepción "circular" de la comunicación y de la causalidad.

La comunicación es concebida como un todo en el que se integran tanto los interlocutores como el mensaje. Se tiene en cuenta la comunicación verbal como la no-verbal o relacional. El concepto de "causalidad circular" es, muy probablemente el que mejor refleja la compleja realidad del conflicto y la múltiple varianza factorial que interviene en el mismo. Factores básicos de carácter lingüístico, normativo, idiosincrático o profesional, etc., como el acceso a la información (la lengua utilizada en la interacción con el recurso social específico); la propia adecuación del recurso (por su horario, características,...); el derecho a acceder al recurso (puede ser conocido o desconocido o estar viciada la información relativa al acceso); el temor racional/irracional a hacer uso del recurso y la baja resistencia a la frustración si la experiencia no es buena o fluida; la experiencia práctica directa del mediador en la gestión de las actitudes, la emociones en juego..., etc.

La acepción "narrativo" hace referencia directa al hecho de que esa categoría es troncal tanto en la dimensión analítica como propositiva del modelo. A través de la metodología circular-narrativa, el mediador debe ser capaz de "sacar a la luz" las diferencias existentes entre los mediados y permitir su operatividad hasta un determinado nivel de presencia. Esta activación del desorden persigue la flexibilidad del sistema y la procura de un nuevo orden (Suares, 1966) surgido de la diferencia consensuada.

En la mediación intercultural, esa pericia práxica, o habilidad para realizar actividades que requieren cierto nivel de complejidad, es especialmente valiosa porque las partes llegan al proceso mediación poseídas de un determinado "orden" previo que, de no ser revelado, como paso previo a su posterior remodelación y cribado, precipitará que, incluso en presencia de un acuerdo entre las partes, éste solo será un acuerdo epidérmico, superficial, o aparente, pero no un acuerdo realmente reparador y consistente en el tiempo y espacio en el que tuvo lugar.

Este modelo tiene una importante aplicación en el terreno de la mediación intercultural porque partiendo de la voluntariedad de las partes para participar proactivamente en la mediación, por un lado; y robusteciendo la figura del mediador, a través del desempeño profesional de su rol, por otro, promueve la legitimación de los mediados favoreciendo de este modo la consolidación del reconocimiento de la diferencia "del otro", y sobre todo, construyendo una visión alternativa de la realidad en disputa, que posibilite una re-visión consensuada del conflicto, por las partes intervinientes.

La valoración previa, por el mediador, del perfil contextual específico, con sus desigualdades y asimetrías, donde va a tener lugar la mediación (escuela, barrio, juzgado, centro de salud, etc.), es un factor de protección muy valioso para que el proceso avance sólidamente y fluya una saludable coordinación entre mediados y mediadores, a través del respeto de los logros alcanzados "en el día a día".

Sara Cobb establece 4 fases en el modelo de mediación circular-narrativo, que sintetizaremos en la Tabla 2. 


\section{PROGRAMACIÓN NEUROLINGÜÍSTICA Y PROCESO DE MEDIACIÓN}

Analizados los tres modelos aplicables en mediación intercultural, y concluyendo que es imprescindible articular un procedimiento de intervención en esa materia, que utilice de una forma integrada presupuestos y técnicas de los tres modelos, es importante destacar que para que las personas mediadas puedan expresar abiertamente sus opiniones, necesidades e intereses y adoptar decisiones responsables en el proceso de mediación es muy recomendable utilizar no solo una metodología integrada, como comentábamos unas líneas más arriba, sino saber implementar una técnica específica de resolución de conflictos que pueda resultar realmente valiosa.

Tabla 2

\begin{tabular}{|c|c|}
\hline $\begin{array}{l}\text { Fase preliminar } \\
\text { (sesión } \\
\text { individual o } \\
\text { conjunta) }\end{array}$ & $\begin{array}{l}\text { a) Se da a conocer a los mediados las características del proceso de } \\
\text { mediación (confidencialidad, imparcialidad, objetividad, flexibilidad...) y } \\
\text { su alcance. } \\
\text { b) Si las partes aceptan voluntariamente participar, se firma un acuerdo } \\
\text { previo, estableciendo el tiempo máximo de ejecución del proceso y todos } \\
\text { los aspectos colaterales (técnicas a implementar, honorarios) a considerar. }\end{array}$ \\
\hline $\begin{array}{l}\text { Fase de } \\
\text { encuentro } \\
\text { dialogado } \\
\text { (sesión } \\
\text { conjunta) }\end{array}$ & $\begin{array}{l}\text { a) Se informa a los mediados del proceso como vehículo de resolución del } \\
\text { conflicto, sus alternativas y las reglas de participación en la mediación } \\
\text { (confidencialidad; sesiones conjuntas e individuales; el mediador solo } \\
\text { podrá compartir con cada parte lo autorizado expresamente por la otra; el } \\
\text { mediador marcará los turnos y supervisará el buen funcionamiento de las } \\
\text { sesiones conjuntas...). }\end{array}$ \\
\hline $\begin{array}{l}\text { Fase de } \\
\text { mediación } \\
\text { (sesiones } \\
\text { individuales) }\end{array}$ & $\begin{array}{l}\text { a) El/la mediador/a trabaja con cada mediado por separado, desplegando } \\
\text { las siguientes pautas: encuadre del problema, fijación de objetivos, } \\
\text { determinación de las contribuciones necesarias para resolver el problema, } \\
\text { análisis de las soluciones intentadas y sistematización de la circularidad. } \\
\text { b) La efectividad de la circularidad depende de la actitud y disposición } \\
\text { personal del mediado para entender que lo que desea obtener está } \\
\text { íntimamente conectado con lo que también quiere la otra parte, } \\
\text { reconociendo el protagonismo recíproco de cada cual en la mediación y el } \\
\text { valor de respetar su punto de vista. }\end{array}$ \\
\hline $\begin{array}{l}\text { Fase de } \\
\text { reflexión interna } \\
\text { del equipo de } \\
\text { mediación }\end{array}$ & $\begin{array}{l}\text { a) El mediador o mediadores reflexiona/n y comparan las diversas } \\
\text { posturas y sus diferencias, con la finalidad de dar paso a la construcción } \\
\text { de una historia alternativa, heredera de la interdependencia desplegada } \\
\text { entre todas ellas. }\end{array}$ \\
\hline $\begin{array}{l}\text { Fase de acuerdo } \\
\text { (sesión } \\
\text { conjunta) }\end{array}$ & $\begin{array}{l}\text { a) Se procede a la narración de la historia alternativa y a la construcción } \\
\text { del acuerdo. } \\
\text { b) La sesión debe contemplar los siguientes aspectos: oír la revisión que } \\
\text { las partes hacen de la historia alternativa (escucha activa); discusión sobre } \\
\text { las ventajas e inconvenientes de cada opción; reconducción de las } \\
\text { posiciones hacia una única posición común de consenso (reconstrucción } \\
\text { de la historia alternativa) y redacción del subsiguiente acuerdo. }\end{array}$ \\
\hline
\end{tabular}

De entre las disponibles y basándome en mi experiencia de más de siete años como mediador al frente del Servicio de Mediación Penal de la Audiencia Provincial de Alicante, recomiendo la utilización de la denominada "Programación Neurolingüística"(PNL), que permite establecer canales de comunicación entre las personas intervinientes en el proceso y 
posibilita tener una perspectiva más realista del conflicto, al objetivarlo al margen de los prejuicios personales que dificultan o impiden la obtención de un acuerdo satisfactorio.

De acuerdo con Bandler \& Grinder, en su publicación de 1981 "Programación neurolingüística y transformación del significado", la PNL es una escuela pragmática de pensamiento que provee herramientas y habilidades para el desarrollo de estados de excelencia en comunicación, promoviendo la flexibilidad de los comportamientos, el pensamiento estratégico y la expresión de las emociones, con la finalidad de optimizar las capacidades personales en el manejo de situaciones conflictivas, a través del desarrollo progresivo de la inteligencia emocional.

El término "programación" se refiere a nuestra aptitud y capacidad para producir y aplicar programas de comportamiento. La expresión "neuro" hace referencia a las percepciones sensoriales que determinan nuestro estado emocional subjetivo. Finalmente, "lingüístico" se refiere a los medios de comunicación humana, tanto verbal como no verbal.

Para aproximarnos al concepto, de una manera gráfica, primero pensemos en un ordenador $\mathrm{y}$ en los procesos informáticos. A continuación imaginemos una persona introduciendo datos en la computadora (cerebro), que procesa, almacena y actualiza esos mismos datos y facilita procesos adaptativos o de cambio, respuestas en suma, de la persona que introduce los datos y que, en todo caso, tendrán repercusión en el medio/contexto/ situación donde la respuesta (comportamiento) repercute. Los datos son las experiencias sensoriales (lo que se oye, siente, palpa, saborea y ve). Todo es procesado y almacenado. Cuando se debe decidir acerca de cómo actuar ante determinada situación, los datos se actualizan y se antepone el que decidirá cómo tomar la decisión, en base a la experiencia previa acumulada, almacenada y procesada. La PNL parte de una experiencia sensorial específica almacenada en el cerebro. Lo importante para trabajar con ella, es conocer la estructura y las condiciones en las que se procesó y almacenó la experiencia.

La PNL es un camino para enriquecer las posibilidades que cada persona tiene y que están disponibles en el mundo que le rodea. Es una habilidad práctica que permite "programar" los resultados que nos proponemos lograr. Nos proporciona herramientas para mejorar la comunicación con uno mismo y con los demás. Nos proporciona elementos para aprender a entrar en el mundo del otro para comprenderlo y aceptarlo. Promueve acuerdos e intercambios y permite ampliar nuestra propia visión de nosotros mismos y de nuestras circunstancias, ofreciendo estrategias para mejorar la calidad de vida personal, familiar y laboral, y permitiéndonos optimizar el uso de los recursos disponibles con que contamos

La PNL puede ayudar muy eficazmente a planificar el proceso de mediación, de acuerdo con los objetivos trazados, y a distinguir las distintas alternativas u opciones viables. Por tratarse de una disciplina en pleno crecimiento, la PNL ha suministrado poderosas herramientas y es aplicada en los siguientes campos:

- En el área de la resolución de conflictos

- En los procesos de comunicación y en el ámbito de las relaciones laborales humanas.

- Para la formación de instructores, formadores y mediadores.

- En contextos educativos y sanitarios

- La PNL otorga gran importancia al contexto y a las relaciones que se establecen dentro de este contexto, "las paredes se sostienen no tanto por los ladrillos como por el cemento que las relaciona".

Principios básicos de la Programación Neurolingüística:

1. El mapa no es el territorio. Ningún mapa refleja el mundo en una forma completa y exacta. 
2. Mente y cuerpo son parte del mismo sistema, se influyen e interaccionan mutuamente.

3. En un sistema dado, el elemento de mayor flexibilidad es el que dominará la situación.

4. Cada comportamiento tiene una intención adaptativa que actúa como un vector del equilibrio que necesita el sistema.

5. Las personas, cuando toman decisiones lo hacen de acuerdo con el mapa que manejan (o el mapa que poseen) y, desde esa perspectiva, es la mejor elección que pueden hacer.

6. No existe el fracaso, sino los resultados, los que tan sólo dan nueva información (retroalimentación o feedback).

7. Las personas tienen los recursos que necesitan para producir cambios. Si no los tienen los pueden aprender.

8. Toda tarea puede ser cumplimentada (o aprendida) si se divide en pequeñas porciones.

9. Cada comportamiento puede servir en algún contexto.

10. El efecto de la comunicación depende de la flexibilidad del emisor. Si algo no funciona, se prueba hacer otra cosa.

\section{EPÍLOGO}

Un enfoque tradicional del conflicto parte de su conceptualización como disputa o desacuerdo entre dos o más partes. Un enfoque sistémico del conflicto, en cambio, profundiza en el vínculo generado entre las personas en conflicto para buscar una solución satisfactoria, ofreciendo a las partes nuevas formas de entendimiento con el fin de que ellas mismas resuelvan su disputa. Desde esta perspectiva no adversarial, el conflicto puede ser definido como "un sistema de conductas que se entrelazan-retroalimentan-complementan canalizando, a través de la acción recíproca de su mutua interrelación, los conflictos o divergencias preexistentes hacia un resultado positivo o constructivo para todas las personas afectadas".

La teoría jerárquica de las necesidades de Maslow constituye una poderosa herramienta cognitiva para entender por qué la mediación es esencial en la resolución de conflictos.

En efecto, la jerarquía de necesidades de Maslow, descrita en su libro Motivación y Personalidad, se describe a menudo como una pirámide que consta de 5 niveles: Los cuatro primeros niveles pueden ser agrupados como necesidades del déficit (deficit needs); el nivel superior se le denomina como una necesidad del ser (being needs). La diferencia estriba en que mientras las necesidades de déficit pueden ser satisfechas, las necesidades del ser son una fuerza impelente continua.

La idea básica de esta jerarquía reside en la creencia de que las necesidades más altas ocupan nuestra atención sólo después de que se hayan satisfecho las necesidades inferiores descritas en la pirámide. Las fuerzas de crecimiento dan lugar a un movimiento hacia arriba en la jerarquía, mientras que las fuerzas regresivas empujan las necesidades prepotentes hacia abajo en la jerarquía.

El escalón básico de Maslow es el de las necesidades fisiológicas, hambre y sed. Cuando el ser humano tiene ya cubiertas estas necesidades empieza a preocuparse por la seguridad de que las va a seguir teniendo cubiertas en el futuro y por la seguridad frente a cualquier daño. Una vez que el individuo se siente físicamente seguro, empieza a buscar la aceptación social; quiere identificarse y compartir las aficiones de un grupo social y quiere que este grupo lo acepte como miembro. Cuando el individuo está integrado en grupos sociales empieza a sentir la necesidad de obtener prestigio, éxito y el reconocimiento de los demás. Finalmente, los individuos que tienen cubiertos todos estos escalones, llegan a la culminación y desean 
sentir que están dando de sí todo lo que pueden aportar, desarrollando entonces su impulso creador.

Si extrapolamos la teoría de Maslow al campo de la resolución de conflictos a través de la mediación, enseguida comprenderemos porque la mediación debe ajustarse a ese proceso funcional y operativo, al que nos referíamos al inicio del presente epígrafe, en el que los participantes desean solucionar, voluntariamente, un problema y comparten el objetivo común de lograr un resultado sensato en forma eficiente y consensuada, separando el problema de las personas involucradas en el mismo, para concentrarse únicamente en los intereses recíprocos y no en las posiciones que marcan las diferencias.

La técnica de la mediación, por tanto, debe basarse en la exploración profunda de los intereses subyacentes en cada uno de los mediados, aportando criterios objetivos, inequívocamente legales, para obtener varias opciones de mutuo beneficio para los mediados que posibiliten la adopción conjunta de la mejor de ellas.

Es importante que los mediados "permanezcan abiertos" a lo largo del proceso de mediación: es el mejor camino para establecer la comunicación entre las partes y mantener y mejorar, si fuera posible así, la interrelación interpersonal entre los mediados, más allá incluso del propio proceso. En efecto, la comunicación es la herramienta más útil y poderosa en el proceso de mediación, lo que obliga al mediador a disponer de, cuantas más mejor, habilidades y recursos comunicativos.

Sin embargo, a pesar de la importancia del manejo de las técnicas descritas en este estudio, para alcanzar unas buenas prácticas en mediación, muy probablemente deberemos valorar la oportunidad de conocer y aplicar otras formulaciones como las de Lederach (1996) o las 3R de Galtung (1998). El propio Lederach menciona los procedimientos populares de mediación utilizados de forma directa y cotidiana por diferentes colectivos urbanos y rurales en diferentes partes del mundo. Esta referencia lederechiana nos traslada inmediatamente a la constatación macroscópica de la gran riqueza de las pautas y patrones de resolución de conflictos constatables en cada cultura, lo que intrínsecamente significa afirmar el vasto contingente de sabiduría popular que podemos y debemos aprovechar para su aplicación en la conformación de una sociedad con un mayor nivel de conciencia en la pacificación de sus propios conflictos, lo que, por extensión, nos lleva directamente al campo de la mediación intercultural como fuente inmediata de resolución de conflictos partiendo del conocimiento del propio significado autóctono que conforma el conflicto.

\section{BIBLIOGRAFÍA}

BANDLER, R. y GRINDER, J. (1983). Reframing: Neurolinguistic programming and the transformation of meaning. Moab, UT: Real People Press.

BUSH, R. A. B. y FOLGER, J. P. (1996). La promesa de la mediación. Cómo afrontar el conflicto a través del fortalecimiento y el reconocimiento de los otros. Buenos Aires: Granica.

COOB, S. (1995a). La neutralidad como práctica discursiva. La construcción y transformación de narrativas en la mediación en comunidades. Curso sobre Negociación y resolución de conflictos. Santa Bárbara: Universidad de California.

COOB, S. (1995b). Una perspectiva narrativa de la mediación. Hacia la materialización de la metáfora de Narración de Historias. Curso sobre Negociación y resolución de conflictos. Santa Bárbara: Universidad de California. 
COOB, S. (1995c). La pragmática del "potenciamiento del protagonismo" en la mediación: una perspectiva narrativa. Curso sobre Negociación y resolución de conflictos. Santa Bárbara: Universidad de California.

COOB, S. y RIFKIN, J. (1991a). "Neutrality as a discursive practice: The construction and transformation of narratives in community mediation". En A. Sarat y S. Silbey (comps), Studies in law, politics and society: Volume 11. Greenwich, CT.: JAI Press.

COOB, S. y RIFKIN, J. (1991b). "Practice and paradox: Deconstructing neutrality in mediation". En Law and Social Inquiry, 161: 35-62.

FISHER, R. y URY, W. (1981). Getting to yes: Negotiating agreement without giving in. Boston: Houghton Mifflin.

GALTUNG, J. (1998). Tras la violencia 3R: reconstrucción, reconciliación, resolución. Gernika: Ggogoratuz.

GIMÉNEZ, C. (2001). "Modelos de mediación y su aplicación en mediación intercultural". Revista Migraciones $\mathrm{n}^{\circ} 10$. Universidad Pontificia de Comillas.

LEDERACH, J. P. (1966). Mediación. Centro de Investigación por la Paz. Gernika: Ggogoratuz.

MASLOW, A. (1991). Motivación y personalidad. Madrid: Ediciones Díaz de Santos.

SUARES, M. (1996). Mediación: Conducción de disputas, comunicación y técnicas. Buenos Aires: Paidós Ibérica.

\section{Breve currículo:}

\section{Carmelo Hernández Ramos}

Licenciado en Psicología. Diplomado en Criminología. Especialista en Violencia de Género y Mediación Penal. Profesor Docente e Investigador del Departamento de Psicología de la Salud de la Universidad de Alicante, Miembro de los grupos de investigación GITE y PsicoCrimiminología de la UA. Técnico de la OJCI de la Audiencia Provincial de Alicante en medidas alternativas a la prisión (programas de reeducación en violencia de género y doméstica; programas de sensibilización y concienciación en seguridad vial), mediación penal reparadora en adultos (plan piloto del CGPJ), acompañamiento asistencial e informativo a víctimas de violencia de género. 